\title{
The influence of storage time on ponazuril concentrations in feline plasma
}

\author{
Sherry Cox ${ }^{\text {Corresp., }}{ }^{,}$Lainey Harvill ${ }^{1}$, Sarah Singleton ${ }^{1}$, Joan Bergman ${ }^{1}$, Becky DeBolt ${ }^{2}$ \\ ${ }^{1}$ Department of Biomedical and Diagnostic Sciences, College of Veterinary Medicine, University of Tennessee, Knoxville, TN, United States \\ 2 Department of Small Animal Clinical Sciences, College of Veterinary Medicine, University of Tennessee, Knoxville, TN, United States \\ Corresponding Author: Sherry Cox \\ Email address: scox6@utk.edu
}

Background. The pharmacokinetics of ponazuril have been determined in several species however, there is very little information on the stability of the drug after storage for long periods of time. This study was undertaken to determine the stability of ponazuril in plasma samples stored at $-80^{\circ} \mathrm{C}$, which is the temperature most commonly used in the author's laboratory.

Method. Spiked plasma samples $(0.3,7.5$, and $15 \mu \mathrm{g} / \mathrm{mL})$ were stored at $-80^{\circ} \mathrm{C}$ for three months. Analysis occurred on the first day and then once a week for the following twelve weeks. The drug was extracted using a chloroform extraction and separated by high performance liquid chromatography using ultraviolet detection.

Results. There was no loss of drug for any concentration for the first four weeks of storage. There was an average loss of less than $5 \%$ from day 35 through day 70 and an average loss of $6 \%$ on day 77 and 84. The data suggest that ponazuril is stable for 4 weeks when stored at $-80^{\circ} \mathrm{C}$ and undergoes minimal loss in the remaining 8 weeks. 
1

2

3

4

5

6

7

8

\section{9} 10 11

The Influence of Storage Time on Ponazuril Concentrations in Feline Plasma

Sherry Cox ${ }^{* 1}$, Lainey Harvill ${ }^{1}$, Sarah Singleton ${ }^{1}$, Joan Bergman ${ }^{1}$, Becky DeBolt ${ }^{2}$

1Department of Biomedical and Diagnostic Sciences and

2Department of Small Animal Clinical Sciences University of Tennessee Knoxville, College of Veterinary Medicine, Knoxville, TN, USA

Corresponding Author:

Sherry Cox, 2407 River Drive, Knoxville, TN, 37996 USA

Email address: scox6@utk.edu

\section{Abstract}

Background. The pharmacokinetics of ponazuril have been determined in several species however, there is very little information on the stability of the drug after storage for long periods of time. This study was undertaken to determine the stability of ponazuril in plasma samples stored at $-80^{\circ} \mathrm{C}$, which is the temperature most commonly used in the author's laboratory.

Method. Spiked plasma samples $(0.3,7.5$, and $15 \mu \mathrm{g} / \mathrm{mL})$ were stored at $-80^{\circ} \mathrm{C}$ for three months. Analysis occurred on the first day and then once a week for the following twelve weeks. The drug was extracted using a chloroform extraction and separated by high performance liquid chromatography using ultraviolet detection.

Results. There was no loss of drug for any concentration for the first four weeks of storage. There was an average loss of less than $5 \%$ from day 35 through day 70 and an 
30

31

32

33

34

35

36

37

38

39

40

41

42

43

44

45

46

47

48

49

50

51

52

53

average loss of $6 \%$ on day 77 and 84 . The data suggest that ponazuril is stable for 4 weeks when stored at $-80^{\circ} \mathrm{C}$ and undergoes minimal loss in the remaining 8 weeks.

\section{Introduction}

Ponazuril (also known as toltrazuril sulfone) is from the triazine class of antiprotozoal drugs and is a metabolite of the drug toltrazuril (Love, et al., 2015).

Triazine compounds have been used in veterinary medicine to treat the harmful effects of protozoa such as Toxoplasma gondii, Coccidia spp., and Isopora, (Stock, et al., 2018).

- - The use of drugs in different species requires knowledge of their pharmacokinetics. An understanding of the pharmacokinetics is necessary for determining the most appropriate dose, route of administration and dosing interval. The determination of accurate drug concentrations is extremely important in the estimation of pharmacokinetic parameters and may impact design of the drug regimen. To determine these properties, it is essential to calculate the concentration of the compound of interest after administration. Because of the importance placed on the validation of bioanalytical methods that are used in the determination of data for pharmacokinetic studies the FDA has established guidelines (FDA, Guidance for industry: Bioanalytical Method Validation). The information in the guidelines applies to bioanalytical procedures such as chromatographic methods. A necessity for the generation of the data is a validated analytical procedure. However, if proper conditions are not maintained for storage the results may not accurately indicate the sample concentration at the time it was determined. For most studies, samples are stored until there is an adequate quantity for analysis, which requires them to be stored, usually 
54 frozen for a period of time. To guarantee accurate results it is essential to determine

55 drug degradation from samples using the storage conditions anticipated for the study.

$56 \quad$ Pharmacokinetic studies of ponazuril have been determined in several species

57 (Laczay, et al., 1995; Epe, et al., 2005; Ghanem, et al., 2008; Love, et al., 2015; Prado,

58 et al., 2011; Dirikolu, et al., 2011; Zou, et al., 2014; Stock, et al., 2018; Furr and

59 Kennedy, 2020). To the author's knowledge there are no other stability articles involving

60 drugs used in felines or triazine drugs. Thus, the intention of this research was to

61 determine if concentrations of ponazuril in feline plasma decreased after storage for 12

62 weeks at $-80^{\circ} \mathrm{C}$ using a validated method (Cox, et al., 2021).

63 Materials \& Methods

64

65

66

\section{Equipment}

The equipment used for ponazuril assessment consisted of a 2695 separation

67 module and a 2487 ultraviolet detector (Waters Milford, MA, USA). Separation was achieved on a Waters Symmetry Shield $\mathrm{RP}_{18}(4.6 \mathrm{~mm} \times 150 \mathrm{~mm}, 5 \mu \mathrm{m})$ column. The

69 mobile phase consisted of $0.1 \%$ formic acid in water and acetonitrile $(50: 50 \mathrm{v} / \mathrm{v})$. The

70 ultraviolet detector was set at $254 \mathrm{~nm}$ and the flow rate was $1.1 \mathrm{~mL} / \mathrm{min}$.

\section{Reagent and solutions}

Ponazuril and diclazuril were purchased from Cayman Chemical (Ann Arbor, MI,

73 USA). Both compounds had a purity greater than $99 \%$. All other solvents and chemicals

74 were acquired from Fisher Scientific (Pittsburg, PA, USA). Stock solutions of ponazuril

$75(100 \mu \mathrm{g} / \mathrm{mL})$ and diclazuril $(100 \mu \mathrm{g} / \mathrm{mL})$, which is the internal standard, were prepared

76 by dissolving appropriate amounts of each compound in methanol. Cat plasma was 
77 fortified with ponazuril to construct daily standard curves $(0.1-25 \mu \mathrm{g} / \mathrm{mL})$. These were

78 accepted if the coefficient of determination $\left(r^{2}\right)$ was greater than 0.99 .

79 Sample Collection

80

Six adult cats from UTCVM faculty and staff were determined to be healthy

based on results of physical examination and history were used. Healthy animals are

routinely used in pharmacokinetic studies in order to prevent distortion of results due to

abnormal metabolism, disease processes or interference from drugs the animal is

taking. Venous blood was collected from the jugular vein of each cat and placed in

lithium heparin tubes. The volume of blood collected from each cat did not exceed $1 \%$

of body weight in kilograms. Enough collected blood was centrifuged to provide plasma

87 for the study. Plasma was pooled into one container and then divided into 3 separate

tubes, and then spiked with one of the ponazuril calibration standards $(0.3,7.5$, and 15

$\mu \mathrm{g} / \mathrm{mL}$ ) that were used in the study. Aliquots from each of the 3 individual standards

were then placed in separate vials labeled Day 1, 7, 14, 21, 28, 35, 42, 49, 56, 63, 70,

77 , and 84 for analysis on those dates. These concentrations were chosen as low

medium and high standards within the linear curve used. Samples were then placed in

the $-80^{\circ} \mathrm{C}$. Day 1 samples were analyzed on that day. Because of animal size and

availability enough plasma was obtained to analyze only one sample for each ponazuril

concentration evaluated.

96

97

Extraction method

Ponazuril was extracted from plasma samples that were thawed one time using a liquid-liquid extraction method (Cox et al., 2021). Frozen plasma samples were thawed at room temperature $\left(22^{\circ} \mathrm{C}\right)$ for $\sim 30$ minutes, vortex-mixed, and $100 \mu \mathrm{l}$ of plasma was 
100 transferred to a screw top tube followed by $10 \mu \mathrm{l}$ of diclazuril $(100 \mu \mathrm{g} / \mathrm{mL}$, internal

101 standard) and $2 \mathrm{~mL}$ chloroform. The tubes were placed on a rocker for 15 minutes and

102 then underwent centrifugation for $20 \mathrm{~min}$ at $1000 \mathrm{xg}$. The organic layer was transferred

103 to a glass tube and evaporated to dryness with nitrogen gas. Samples were

104 reconstituted in $250 \mu \mathrm{L}$ of mobile phase and $100 \mu \mathrm{L}$ was analyzed.

105 Statistical analysis

106 Comparative changes in the actual values of different measured ponazuril

107 concentrations in plasma samples were used to summarize the effect of storage length

108 on stability of the drug.

\section{Results}

84 (Figure 1A-D and Table 1). The actual values of the different measured ponazuril concentrations and the percent variation of the concentration compared to the starting concentration are reported in Table 1. Ponazuril concentrations were determined in all samples. There was no loss of drug for any concentration (low, medium or high) for the first four weeks (days 1 through 28 ) of storage at $-80^{\circ} \mathrm{C}$. Please refer to the Figure and

117 Table for the remainder of the results. previously validated (Cox et al., 2021). The method produced a linear curve over the concentration range used $(0.1-25 \mu \mathrm{g} / \mathrm{ml})$ with a lower limit of quantification of 0.1 $\mu \mathrm{g} / \mathrm{mL}$. The intraday and interday variability ranged from 3.7 to $10 \%$ and 2.1 to $5.5 \%$ while the average ponazuril recovery was $99 \%$ and the average recovery of diclazuril was $94 \%$. Calibration curves were analyzed each day of plasma analysis. 
124

125

126

127

128

129

130

131

132

133

134

135

136

137

138

139

140

141

142

143

144

145

146

147

\section{Discussion}

In order to determine the optimal storage time for ponazuril samples at $-80^{\circ} \mathrm{C}$, plasma was collected from healthy felines and pooled in order to reduce the effects of inter-individual variability. A validated method of analysis was applied to the samples to determine the effect of storage duration. Plasma samples spiked with various amounts of ponazuril that fell within a validated linear concentration range and stored in a $-80^{\circ} \mathrm{C}$ freezer for 84 days were used. One limitation to the study was a lack of duplicate samples for the analysis. The analysis of only one sample did not allow for any statistical analysis.

Ponazuril was detected in all concentrations for the entire 84 days. For the first 28 days, there was no change in any of the concentrations. Indicating that the drug is stable after storage for that length of time. After 28 days, there was a slight loss of drug for all three concentrations. The average loss was $4 \%$ or less for days 35 through 63 , which would still not have an impact on higher concentrations and have a minimal impact on lower concentrations. The samples should still be viable for this period of time. On day 70 , there was an average loss of $5 \%$ and on days 77 and 84 there was an average loss of $6 \%$. The loss on day 84 was greater for the 0.3 and 7.5 than the 15 $\mu \mathrm{g} / \mathrm{mL}$ standard. Overall, the average loss from day 7 though day 84 was $2 \%, 4 \%$ and $2 \%$ for $0.3,7.5$ and $15 \mu \mathrm{g} / \mathrm{mL}$, respectively.

To the author's knowledge there are no other stability articles involving drugs used in felines or triazine drugs. There is a paucity of information in the literature about the storage stability of drugs in biological samples in general. Determination of the concentrations in biological samples is fundamental to describing pharmacokinetic 
148 parameters which in turn leads to appropriate dosing regimens. Therefore, it is

149 imperative to determine the effect that storage can have on drug stability.

150

151

\section{Conclusions}

152

153

The intention of this study was to determine the effect of storage duration at -

$80^{\circ} \mathrm{C}$ on the stability of ponazuril concentrations in plasma. In summary, plasma

samples, containing ponazuril can be stored for 28 days with no loss of drug. By

applying the FDA Bioanalytical Guidelines (FDA, Guidance for industry: Bioanalytical

Method Validation) for method development that states a value should be within $15 \%$

158

deviation from the standard all of the samples were stable for 84 days when stored at -

$80^{\circ} \mathrm{C}$. This study provides much needed information on the stability of ponazuril plasma samples stored at $-80^{\circ} \mathrm{C}$.

161

162

163

164

165

166

167

168

169

170

171

172

173

\section{References}

Cox S, Harvill L, Singleton S, Bergman J, DeBolt B. Bioanalytical RP-HPLC method for the determination of ponazuril in plasma. Biomedical Chromatography https://doi.org/10.1002/bmc.5210.

Dirikolu L, Karpiesiuk W, Lehner AF, Tobin T. Toltrazuril sulfone salt: synthesis, analytical detection and pharmacokinetics in the horse. Journal of Veterinary Pharmacology and Therapeutics 2011; 35:265-274.

FDA, Guidance for industry: Bioanalytical Method Validation 2018. http://www.fda.gov/downloads/Drugs/GuidanceComplianceRegulatoryInformation/ Guidances/UCM070107.pdf. 
174 Furr M, Kennedy T. Effects of coadministration of corn oil and ponazuril on serum and 175 cerebrospinal fluid concentrations of ponazuril in horses. Journal of Veterinary $176 \quad$ Internal Medicine 2020; 34:1321-1324.

177 Love D, Gibbons P, Fajt, Jones M. Pharmacokinetics of single-dose oral ponazuril in 178 weanling goats. Journal of Veterinary Pharmacology and Therapeutics 2015; 39: $179 \quad 305-308$.

180 Prado ME, Ryman JT, Boileau MJ, Martin-Jimenez T, Meibohm B. Pharmacokinetics of 181 ponazuril after oral administration to healthy llamas (Lama Glama). American Journal of 182 Veterinary Research 2011; 72:1386-1389.

183 Stock ML, Elazab ST, Hsu WH. Review of triazine antiprotozoal drugs used in 184 veterinary medicine. Journal of Veterinary Pharmacology and Therapeutics 2018: $185 \quad 41: 184-194$.

186 Zou M, Guo G, Zhao Y, Zhang Q. Detection, quantifications, and pharmacokinetics of ponazuril 187 in healthy swine. Journal of Veterinary Pharmacology and Therapeutics 2014; 37:598-602. 
Figure 1

Ponazuril Drug Loss

Percent ponazuril loss in plasma over 84 days (A) all 3 concentrations (B) $0.3 \mu \mathrm{g} / \mathrm{mL}$, (C) 7.5 $\mu \mathrm{g} / \mathrm{ml}$, (D) $15 \mu \mathrm{g} / \mathrm{ml}$.
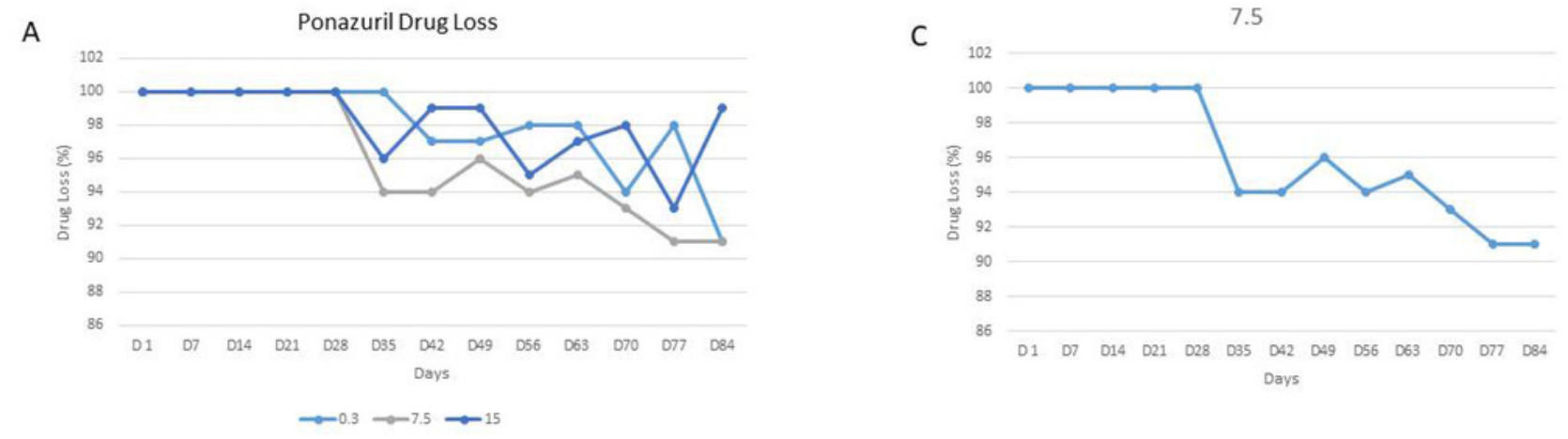

B

0.3

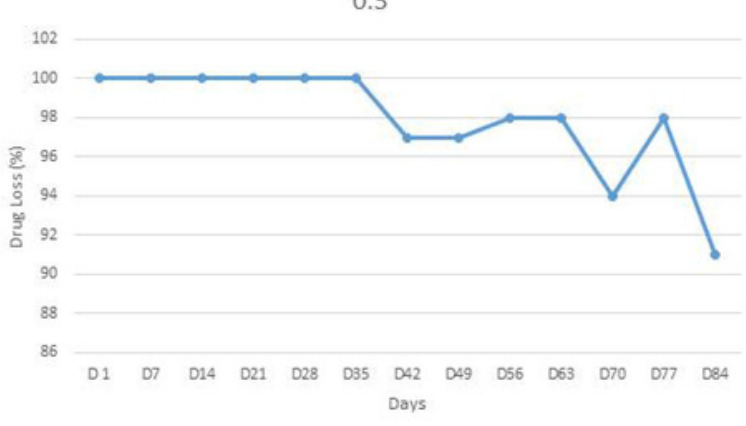

D

15

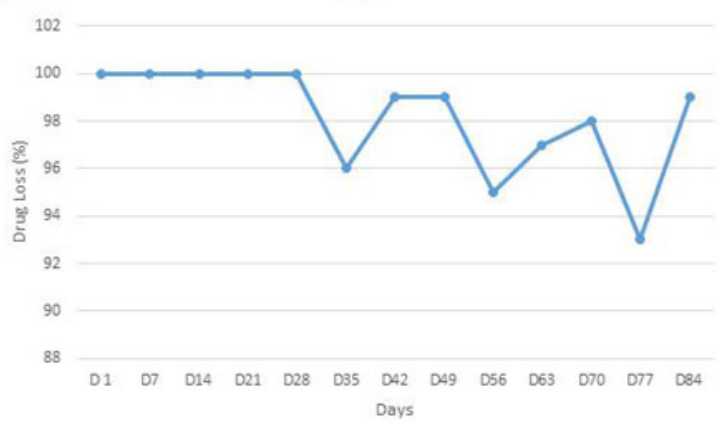




\section{Table $\mathbf{1}$ (on next page)}

Ponazuril stability information for 84 days after storage at $-80^{\circ} \mathrm{C}$.

Concentration results reported in $\mu \mathrm{g} / \mathrm{mL} ; \mathrm{n}=1 ;$ * Day 1 samples were not frozen but analyzed immediately after spiking. 
1 Table 1. Ponazuril stability information for 84 days after storage at $-80^{\circ} \mathrm{C}$.

\begin{tabular}{|c|c|c|c|c|c|c|c|c|c|c|c|c|c|}
\hline & \multicolumn{13}{|c|}{ Concentration at different days of storage } \\
\hline $\begin{array}{l}\text { Starting } \\
\text { conc. }\end{array}$ & $\begin{array}{c}\text { Day } \\
1^{*}\end{array}$ & Day 7 & $\begin{array}{c}\text { Day } \\
14\end{array}$ & $\begin{array}{c}\text { Day } \\
21\end{array}$ & $\begin{array}{c}\text { Day } \\
28\end{array}$ & $\begin{array}{c}\text { Day } \\
35\end{array}$ & \begin{tabular}{|c|} 
Day \\
42
\end{tabular} & $\begin{array}{c}\text { Day } \\
49\end{array}$ & $\begin{array}{c}\text { Day } \\
56\end{array}$ & $\begin{array}{c}\text { Day } \\
63\end{array}$ & $\begin{array}{c}\text { Day } \\
70\end{array}$ & $\begin{array}{c}\text { Day } \\
77\end{array}$ & $\begin{array}{c}\text { Day } \\
84\end{array}$ \\
\hline 0.3 & 0.3 & 0.3 & 0.3 & 0.3 & 0.3 & 0.3 & 0.291 & 0.291 & 0.294 & 0.294 & 0.282 & 0.294 & 0.273 \\
\hline 7.5 & 7.5 & 7.5 & 7.5 & 7.5 & 7.5 & 7.05 & 7.05 & 7.2 & 7.05 & 7.1 & 7.0 & 6.8 & 6.8 \\
\hline \multirow[t]{3}{*}{15} & 15.0 & 15.0 & 15.0 & 15.0 & 15.0 & 14.4 & 14.85 & 14.85 & 14.25 & 14.55 & 14.7 & 13.95 & 14.85 \\
\hline & & & & & & & & & & & & & \\
\hline & \multicolumn{13}{|c|}{ Percentage change in concentration from starting concentration } \\
\hline 0.3 & 0 & 0 & 0 & 0 & 0 & 0 & -3 & -3 & -2 & -.2 & -6 & -2 & -9 \\
\hline 7.5 & 0 & 0 & 0 & 0 & 0 & -6 & -6 & -4 & -6 & -5 & -6 & -9 & -9 \\
\hline 15 & 0 & 0 & 0 & 0 & 0 & -4 & -1 & -1 & -5 & -3 & -2 & -7 & -1 \\
\hline
\end{tabular}
immediately after spiking. 